\title{
Effect of carbonate minerals on the thermal stability of fertilisers containing ammonium nitrate
}

\author{
Dariusz Popławski ${ }^{1}$. Józef Hoffmann ${ }^{1} \cdot$ Krystyna Hoffmann $^{1}$
}

Received: 28 August 2015/Accepted: 26 December 2015/Published online: 28 January 2016

(C) The Author(s) 2016. This article is published with open access at Springerlink.com

\begin{abstract}
Fertilisers containing ammonium nitrate are the most efficient sources of nitrogen used in agriculture. The major hazard associated with production, storage and transport of materials containing this compound is its liability to rapid decomposition, or even detonation under certain conditions. Properly selected calcium and magnesium carbonates may increase the thermal stability of ammonium nitrate. The aim of this research was to determine the influence of the carbonate mineral type and composition on phase transitions and decomposition process of fertiliser-grade ammonium nitrate. The article focuses on the methodology of thermal analysis of samples containing ammonium nitrate with carbonates and points out the phenomena and thermal characteristics that should be taken into consideration when testing fertiliser mixtures. Two different sample preparation methods allowed for investigating processes that may occur in inappropriate storage and transport conditions as well as during the production of fertiliser. The measurements were taken using techniques of differential thermal analysis and thermogravimetry coupled with mass spectrometry. The results showed that too high a level of carbonates reactivity can cause problems during the production of fertiliser, reducing the effectiveness of the filler in a final product.
\end{abstract}

Keywords Ammonium nitrate $\cdot$ Fertiliser $\cdot$ Thermal stability $\cdot$ Decomposition $\cdot$ Carbonates

Dariusz Popławski

dariusz.poplawski@pwr.edu.pl

1 Department of Technology and Chemical Processes, Wroclaw University of Technology, Smoluchowskiego 25, 50-372 Wrocław, Poland

\section{Introduction}

Nitrogen is one of the most important macronutrients for plant growth. Therefore, fertilisers containing this element are an indispensable part of modern sustainable agriculture. Currently used preparations mainly include ammonium nitrate, calcium ammonium nitrate (CAN), urea and solutions of urea and ammonium nitrate (UAN) [1]. Nitrogen in these fertilisers is present in different forms. The most assimilable among them is nitrate ion $\mathrm{NO}_{3}^{-}$. Ammonium form $\mathrm{NH}_{4}^{+}$has to undergo a nitrification process before plants can effectively use the contained nitrogen. Thus, formulations containing ammonium nitrate are the most efficient sources of nitrogen, providing controlled intake evenly distributed in time [2,3]. Fertilisers containing ammonium nitrate as a dominant component may, however, excessively acidify the soil [4]. In those terms, much better fertilisers, with a lower environmental impact, include CAN-type fertilisers with a nitrogen content of up to 28 mass\%. They are comprised of ammonium nitrate with the addition of properly selected filler. Various types of carbonate minerals are used for this purpose, mainly dolomite, limestone and anhydrite [2,5]. Acidification of the soil after application of CAN fertiliser is significantly lower, and additionally, it is enriched in elements such as calcium and magnesium [6]. Field studies also confirmed that responses of growth characteristics are better for CAN than for urea or ammonium sulphate [7].

Apart from agricultural aspects, the filler addition is mainly intended to stabilise the ammonium nitrate contained in the fertiliser. It is commonly known that at elevated temperature or under impact, this compound is susceptible to a rapid exothermic decomposition and in extreme cases, even detonation $[8,9]$. Currently accepted theories assume that decomposition may occur by two 
different mechanisms. In a temperature range of 200-300 ${ }^{\circ} \mathrm{C}$, the ionic mechanism dominates, wherein the formation of the nitronium ion $\left(\mathrm{NO}_{2}^{+}\right)$is the rate-limiting step of the whole process. Above $290{ }^{\circ} \mathrm{C}$, decomposition proceeds using the free radical mechanism and the homolysis of nitric acid, leading to the formation of nitrous oxide with the hydroxyl radical being considered the ratecontrolling step. Regardless of the mechanism, the first step of decomposition is always an endothermic dissociation of ammonium nitrate to ammonia and nitric acid. All further reactions are exothermic [10-13]. However, depending on the surface-to-volume ratio of the sample, endothermic surface evaporation may dominate the decomposition process $[14,15]$. Recent studies suggest that this phenomenon may be associated with a chemical process, i.e. dissociation of ammonium nitrate, as well as with a physical sublimation or vaporisation of the whole molecule, which is also stable in the gas phase [16, 17].

Due to the complexity of the overall ammonium nitrate decomposition process, many factors may influence its course. The thermal stability of this salt can be reduced by various impurities, among which the most dangerous are chlorides, acids and some organic compounds [18-22]. This property of ammonium nitrate was the cause of many devastating events, both accidental and deliberate [10, 23-26]. Therefore, interactions of various substances with this salt were extensively investigated over the past few decades. Some of these compounds have proved to positively influence the thermal stability of ammonium nitrate. Nevertheless, when choosing the best additive for that purpose, its suitability for plants must also be taken into consideration. For this reason, carbonates are one of the most frequently used fillers for improving the safety of fertilisers based on ammonium nitrate. A few researchers studied the influence of such individual pure compounds [10, 27]. However, due to economic aspects, in industrial production, natural minerals with a more complex composition are used, mainly consisting of calcium and magnesium carbonates in various proportions [2].

The carbonate mineral reacts with the ammonium nitrate in decomposition conditions. Interactions between each component may be very complex [28]. However, they are often simplified to the following general reaction Eqs. (1) and (2).

$2 \mathrm{NH}_{4} \mathrm{NO}_{3}+\mathrm{CaCO}_{3} \rightarrow \mathrm{Ca}\left(\mathrm{NO}_{3}\right)_{2}+2 \mathrm{NH}_{3}+\mathrm{H}_{2} \mathrm{O}+\mathrm{CO}_{2}$

$$
2 \mathrm{NH}_{4} \mathrm{NO}_{3}+\mathrm{MgCO}_{3} \rightarrow \mathrm{Mg}\left(\mathrm{NO}_{3}\right)_{2}+2 \mathrm{NH}_{3}+\mathrm{H}_{2} \mathrm{O}
$$$$
+\mathrm{CO}_{2}
$$

Ammonia is one of the products of these reactions. It strongly inhibits undesirable exothermic processes that may occur in the fertiliser, thus improving its safety.
Furthermore, both reactions are endothermic (Table 1) [29]. Therefore, they can reduce the heat release in an emergency situation. In addition, suitable filler may positively influence physical and mechanical properties of the fertiliser, such as hardness of the granules or the porosity and bulk density of the product [30]. Effective filler should therefore be reactive in contact with ammonium nitrate in hazardous conditions. At the production stage, it should, however, react as little as possible, while still maintaining the proper composition of the fertiliser and providing the desired physical properties [31, 32]. In this context, not every carbonate mineral is suitable for fertiliser production, and the selection of effective filler requires knowledge, experience and preliminary tests.

Thermal analysis is a typical method for testing the stability of different samples. In case of ammonium nitrate, it enables to investigate its phase transitions and decomposition processes. The influence of selected additives on thermal behaviour of ammonium nitrate can also be tested using this technique [33-35]. However, the measurement results do not provide any information regarding the liability of selected mixture to detonation. According to the current European Union legislation, only fertilisers containing more than 28 mass\% of nitrogen have to be tested for detonation potential [36]. Standard CAN-type fertilisers containing up to 27.5 mass $\%$ of nitrogen are assumed to be resistant to this phenomenon. However, recent research proves that this assumption is not applicable to all nitrogen fertilisers with filler and many of them can be easily sensitised to detonation, unless they contain more than 30 mass \% of carbonates [25, 37]. Therefore, thermal analysis may be used for preliminary assessment of filler suitability to be used in nitrogen fertilisers, while commercial production must be preceded by further industrial tests, including granulation of selected mixture, its density and porosity control, and detonation test. The latter may be performed using standard direct EU procedure or recently proposed indirect method utilising mathematical equations based on values of selected properties of fertiliser [8, 36].

The aim of this study was to determine the influence of the carbonate mineral type and composition on phase transitions and decomposition process of fertiliser-grade ammonium nitrate. The article focuses on the methodology of thermal analysis of samples containing ammonium nitrate with carbonates and points out the phenomena and thermal characteristics that should be taken into consideration when testing fertiliser mixtures. In contrast to a few similar articles, the composition of tested mixtures directly reflected the nitrogen content typical for CAN-type fertilisers. Two different sample preparation methods allowed to reflect and measure thermal effects that may occur during the production of fertiliser with specific filler or in inappropriate conditions of storage and transport of a final product. 
Table 1 Standard enthalpies, $\Delta H_{\mathrm{r}}^{\circ}$, and Gibbs energies, $\Delta G_{\mathrm{r}}^{\circ}$, of reactions of ammonium nitrate with calcium carbonate (1) and magnesium carbonate (2), $\mathrm{kJ} / \mathrm{mol} \mathrm{NH}_{4} \mathrm{NO}_{3}$

\begin{tabular}{|c|c|c|c|c|}
\hline \multirow[t]{2}{*}{ Temperature $/{ }^{\circ} \mathrm{C}$} & \multicolumn{2}{|c|}{ Reaction (1) with $\mathrm{CaCO}_{3}$} & \multicolumn{2}{|c|}{ Reaction (2) with $\mathrm{MgCO}_{3}$} \\
\hline & $\Delta H_{\mathrm{r}}^{\circ} / \mathrm{kJ} \mathrm{mol}^{-1}$ & $\Delta G_{\mathrm{r}}^{\circ} / \mathrm{kJ} \mathrm{mol}^{-1}$ & $\Delta H_{\mathrm{r}}^{\circ} / \mathrm{kJ} \mathrm{mol}^{-1}$ & $\Delta G_{\mathrm{r}}^{\circ} / \mathrm{kJ} \mathrm{mol}^{-1}$ \\
\hline 100 & 132.1 & 27.8 & 149.9 & 46.1 \\
\hline 125 & 131.2 & 20.8 & 149.0 & 39.1 \\
\hline 150 & 125.7 & 14.2 & 143.5 & 32.5 \\
\hline 200 & 117.7 & 1.6 & 135.7 & 19.9 \\
\hline 250 & 116.0 & -10.6 & 134.1 & 7.8 \\
\hline 300 & 114.5 & -22.7 & 133.0 & -4.2 \\
\hline 350 & 113.3 & -34.6 & 132.2 & -16.2 \\
\hline
\end{tabular}

\section{Materials and methods}

\section{Sample preparation}

Fertiliser-grade ammonium nitrate used in the study was taken directly after the industrial neutralisation step and was supplied by one of the domestic producers of nitrogen fertilisers. Five air-dried minerals, with a grain size $<125 \mu \mathrm{m}$, obtained from selected domestic and foreign deposits, were used as fillers. Their composition was determined after mineralisation with hydrochloric acid. Insoluble residue, consisting mainly of silicon dioxide, was separated on a filter paper, calcined in $900{ }^{\circ} \mathrm{C}$ and weighed. Calcium, magnesium, iron and aluminium content was determined using complexometric titration with EDTA. Spectrophotometric method was used for analysis of chlorine and sulphur concentration. Trace elements content was determined using ICP-AES. Moisture content and loss on ignition up to $1000{ }^{\circ} \mathrm{C}$ were calculated on the basis of gravimetric measurements. BET surface area of tested fillers was calculated from nitrogen adsorption measurements taken using Micromeritics ASAP 2050 Extended Pressure device. Characteristics of tested minerals are given in Table 2. Type of filler was determined on the basis of $\mathrm{CaO}$ to- $\mathrm{MgO}$ ratio, according to Frolova's classification of carbonate rocks [38]. Filler W5 is commercially available in a partially calcined form. Based on the weight loss on ignition up to $1000{ }^{\circ} \mathrm{C}$, it can be calculated that carbonates constitute not more than 20 mass\% of the W5 filler, which confirms that it consists mainly of calcium oxide. Therefore, Frolova's classification is not applicable in this case.

Mixtures tested in the present study were prepared in accordance with two different methods. In the first method, $5.000 \mathrm{~g}( \pm 0.001 \mathrm{~g})$ of ammonium nitrate was thoroughly triturated in a mortar with $1.363 \mathrm{~g}( \pm 0.001 \mathrm{~g})$ of carbonate mineral. In this case, all reactions between ammonium nitrate and filler, which would occur at an elevated temperature during the industrial production of fertiliser, were registered during thermal analysis. The second sample preparation method simulated production of CAN fertiliser, where filler is added to molten ammonium nitrate. During this step, $20.000 \mathrm{~g}( \pm 0.001 \mathrm{~g})$ of ammonium nitrate with 5 mass $\%$ addition of water was heated up to $150{ }^{\circ} \mathrm{C}$ in order to melt the salt. Next, $5.455 \mathrm{~g}( \pm 0.001 \mathrm{~g})$ of the selected filler was added and the whole mixture was stirred for $10 \mathrm{~min}$, keeping the temperature at $150{ }^{\circ} \mathrm{C}$. Then, the melt was poured onto the ceramic plate and after solidification, it was roughly ground and dried at $105{ }^{\circ} \mathrm{C}$ for $2 \mathrm{~h}$. The cooled mixture was then thoroughly triturated in a mortar. The processes registered during thermal analysis of samples prepared in accordance with the second method reflected the thermal changes that may occur in fertiliser during its storage or transport in inappropriate conditions. Regardless of the sample preparation procedure, the total nitrogen content in the tested mixtures was 27.5 mass\%, which is typical for CAN fertilisers.

\section{Thermal analysis instruments and procedures}

The measurements were taken using techniques of differential thermal analysis and thermogravimetry, coupled with mass spectrometry (DTA-TG-MS). A thermal analyser STA 449 F3 with a thermobalance and the mass spectrometer QMS 403 C, Netzsch, were used. The mass of the tested samples, regardless of their preparation procedure, was $127.5 \pm 0.5 \mathrm{mg}$, so that they always contained $100 \mathrm{mg}$ of ammonium nitrate. The sample was placed in a $0.3 \mathrm{~mL}$ alumina crucible and heated to $450{ }^{\circ} \mathrm{C}$ at $5{ }^{\circ} \mathrm{C} \mathrm{min}{ }^{-1}$

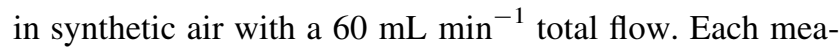
surement was preceded by heating the empty crucible to $600{ }^{\circ} \mathrm{C}$ in order to remove any impurities and a correction to $500{ }^{\circ} \mathrm{C}$ for compensation of the thermal effects associated with the characteristics of the crucible. Before each measurement, the furnace chamber was evacuated three times and filled with synthetic air. In the same way, for comparison purposes, a $100 \mathrm{mg}$ sample of ammonium nitrate without the addition of any filler was also examined. The results were 
Table 2 Characteristics of fillers used for preparation of tested CAN-type fertiliser mixtures

\begin{tabular}{|c|c|c|c|c|c|}
\hline & W1 & W2 & W3 & W4 & W5 \\
\hline $\mathrm{CaO} / \mathrm{mass} \%$ & 30.11 & 39.05 & 48.49 & 53.96 & 84.82 \\
\hline $\mathrm{MgO} / \mathrm{mass} \%$ & 20.09 & 12.84 & 2.52 & 1.15 & 4.03 \\
\hline $\mathrm{Fe}_{2} \mathrm{O}_{3} /$ mass $\%$ & 0.32 & 0.14 & 0.17 & 0.34 & 0.18 \\
\hline $\mathrm{Al}_{2} \mathrm{O}_{3} /$ mass $\%$ & 0.26 & 0.19 & 0.32 & 0.21 & 0.34 \\
\hline $\mathrm{SiO}_{2} /$ mass $\%$ & 1.18 & 0.50 & 5.34 & 0.61 & 0.83 \\
\hline $\mathrm{Cl}^{-} /$mass $\%$ & 0.005 & 0.004 & 0.035 & 0.040 & 0.004 \\
\hline $\mathrm{SO}_{3} /$ mass $\%$ & 0.049 & 0.006 & 0.119 & 0.248 & 0.215 \\
\hline $\mathrm{Cu} / \mathrm{ppm}$ & 6.9 & 46.2 & 41.1 & 17.0 & 26.8 \\
\hline $\mathrm{Mn} / \mathrm{ppm}$ & 62.6 & 195.0 & 72.1 & 32.1 & 70.3 \\
\hline $\mathrm{Cr} / \mathrm{ppm}$ & 1.9 & 6.3 & 8.7 & 2.4 & 4.2 \\
\hline $\mathrm{Ni} / \mathrm{ppm}$ & 2.0 & 14.1 & 3.3 & 2.2 & 3.5 \\
\hline $\mathrm{Pb} / \mathrm{ppm}$ & 1.2 & 1.3 & 2.0 & 2.3 & 1.2 \\
\hline Moisture content/mass $\%$ & 0.18 & 0.20 & 0.94 & 0.36 & 0.87 \\
\hline $\begin{array}{l}\text { Loss on ignition } \\
\left(1000^{\circ} \mathrm{C}\right) / \text { mass } \%\end{array}$ & 47.14 & 45.38 & 43.76 & 42.37 & 9.12 \\
\hline$S_{\mathrm{BET}} / \mathrm{m}^{2} \mathrm{~g}^{-1}$ & 0.9 & 0.6 & 3.8 & 3.4 & 2.2 \\
\hline Tapped density/g $\mathrm{cm}^{-3}$ & 1.70 & 1.64 & 1.41 & 1.18 & 0.56 \\
\hline $\mathrm{CaO} / \mathrm{MgO}$ ratio & 1.5 & 3.0 & 19.2 & 46.9 & 21.0 \\
\hline Filler type & Dolomite & $\begin{array}{l}\text { Calcitic } \\
\text { dolomite }\end{array}$ & $\begin{array}{l}\text { Slightly dolomitic } \\
\text { limestone }\end{array}$ & $\begin{array}{l}\text { Slightly dolomitic } \\
\text { limestone }\end{array}$ & $\begin{array}{c}\text { n/a (partially } \\
\text { calcined } \\
\text { limestone) }\end{array}$ \\
\hline
\end{tabular}

analysed using professional software supplied by the manufacturer of the measuring equipment.

\section{Results and discussion}

\section{Pure ammonium nitrate}

The result of the thermal analysis of ammonium nitrate without the addition of any filler is shown in Fig. 1. During heating, ammonium nitrate underwent endothermic phase transitions specific to this compound at temperatures given in Table 3. In the range of $220-300{ }^{\circ} \mathrm{C}$, the exothermic decomposition of ammonium nitrate occurred, which was accompanied by a total loss of the sample mass. The exotherm maximum was reached at temperature close to $264{ }^{\circ} \mathrm{C}$. The shape of the DTA curve may suggest a multistep autocatalytic process, accelerated by the reaction products formed during decomposition of ammonium nitrate. Analysis of the mass spectrometry results (Fig. 2) confirmed the presence of water $(\mathrm{m} / \mathrm{z}=18)$ and nitrogen oxides $(\mathrm{m} / \mathrm{z}=30, \mathrm{~m} / \mathrm{z}=44, \mathrm{~m} / \mathrm{z}=46)$ in a gas phase, while no compounds containing carbon, e.g. carbon dioxide, were observed $(\mathrm{m} / \mathrm{z}=12)$. The beginning of the gaseous products evolution confirms that exothermic decomposition of ammonium nitrate starts at about $218{ }^{\circ} \mathrm{C}$.

\section{Mixtures with fillers: I sample preparation method}

The content of selected fillers in the tested samples significantly influenced the nature and course of the various changes occurring in the ammonium nitrate. In the case of the first method of sample preparation, the addition of filler W1 (Fig. 3) and W2 (Fig. 5) resulted in a similar effect. For both carbonate minerals, the temperature of the first observed phase transition, i.e. from structure IV to III, increased by $7{ }^{\circ} \mathrm{C}$. The second phase transition, occurring at around $86{ }^{\circ} \mathrm{C}$, disappeared in these CAN mixtures. The lack of transformation III $\rightarrow$ II is typical for ammonium nitrate having a low moisture content. Added fillers probably absorbed some of the water from the ammonium nitrate, causing the above-described effect. The temperature of the phase transition II $\rightarrow$ I and the melting point remained practically unchanged in the first two CAN samples. Above $200{ }^{\circ} \mathrm{C}$, a gradual increase in the DTA curve can be seen in Figs. 3 and 5, up to a temperature of $231{ }^{\circ} \mathrm{C}$ in the case of mixture with filler $\mathrm{W} 1$ and up to $222{ }^{\circ} \mathrm{C}$ for a sample containing dolomite $\mathrm{W} 2$. Then, the rapid endothermic processes associated with the reactions of filler with ammonium nitrate began, according to simplified Eqs. (1) and (2). It is evidenced by the evolution of $\mathrm{CO}_{2}(\mathrm{~m} / \mathrm{z}=12)$ registered in MS measurements (Figs. 4, 6). In an emergency situation, these heat-consuming reactions may suppress the degradation of 
Fig. 1 Result of DTA-TG measurement of the fertilisergrade ammonium nitrate sample

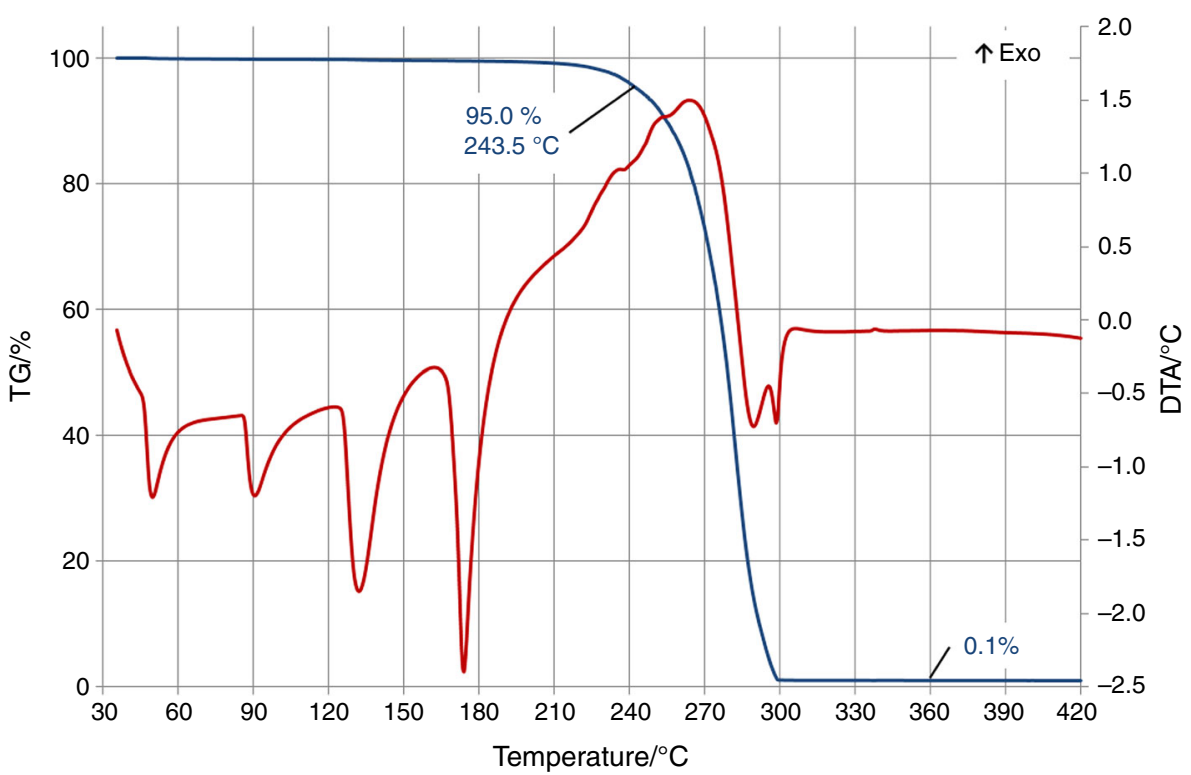

Table 3 Thermal characteristics of ammonium nitrate and CAN samples with different fillers

\begin{tabular}{|c|c|c|c|c|c|c|c|}
\hline \multirow[t]{2}{*}{ Filler } & \multirow{2}{*}{$\begin{array}{l}\text { Sample } \\
\text { preparation } \\
\text { method }\end{array}$} & \multicolumn{4}{|c|}{ Temperature of phase transitions $/{ }^{\circ} \mathrm{C}$} & \multirow{2}{*}{$\begin{array}{l}\text { Endotherm } \\
\text { beginning } /{ }^{\circ} \mathrm{C}\end{array}$} & \multirow{2}{*}{$\begin{array}{l}\text { Exotherm } \\
\text { maximum } /{ }^{\circ} \mathrm{C}\end{array}$} \\
\hline & & $\mathrm{IV} \rightarrow \mathrm{III}$ & $\mathrm{III} \rightarrow \mathrm{II}$ & $\mathrm{II} \rightarrow \mathrm{I}$ & Melting & & \\
\hline- & - & 46.6 & 86.5 & 125.8 & 168.9 & - & 263.8 \\
\hline \multirow[t]{2}{*}{ W1 } & I & 53.7 & - & 126.6 & 169.3 & 231.0 & 317.6 \\
\hline & II & 53.6 & 87.7 & 126.4 & 169.4 & 226.1 & 318.1 \\
\hline \multirow[t]{2}{*}{ W2 } & I & 53.7 & - & 126.7 & 168.7 & 222.4 & 326.6 \\
\hline & II & 53.1 & 86.8 & 126.3 & 168.1 & 218.7 & 318.0 \\
\hline W3 & I & 53.7 & - & 126.2 & 159.5 & 232.2 & 301.1 \\
\hline \multirow[t]{2}{*}{ W4 } & I & 53.8 & - & 126.3 & 154.3 & 222.7 & 298.9 \\
\hline & II & 52.6 & 87.8 & 127.4 & $103.7-144.6$ & 211.3 & 281.0 \\
\hline W5 & I & 53.5 & 89.2 & - & - & 286.2 & 314.6 \\
\hline
\end{tabular}

Fig. 2 Result of MS measurement of the fertilisergrade ammonium nitrate sample

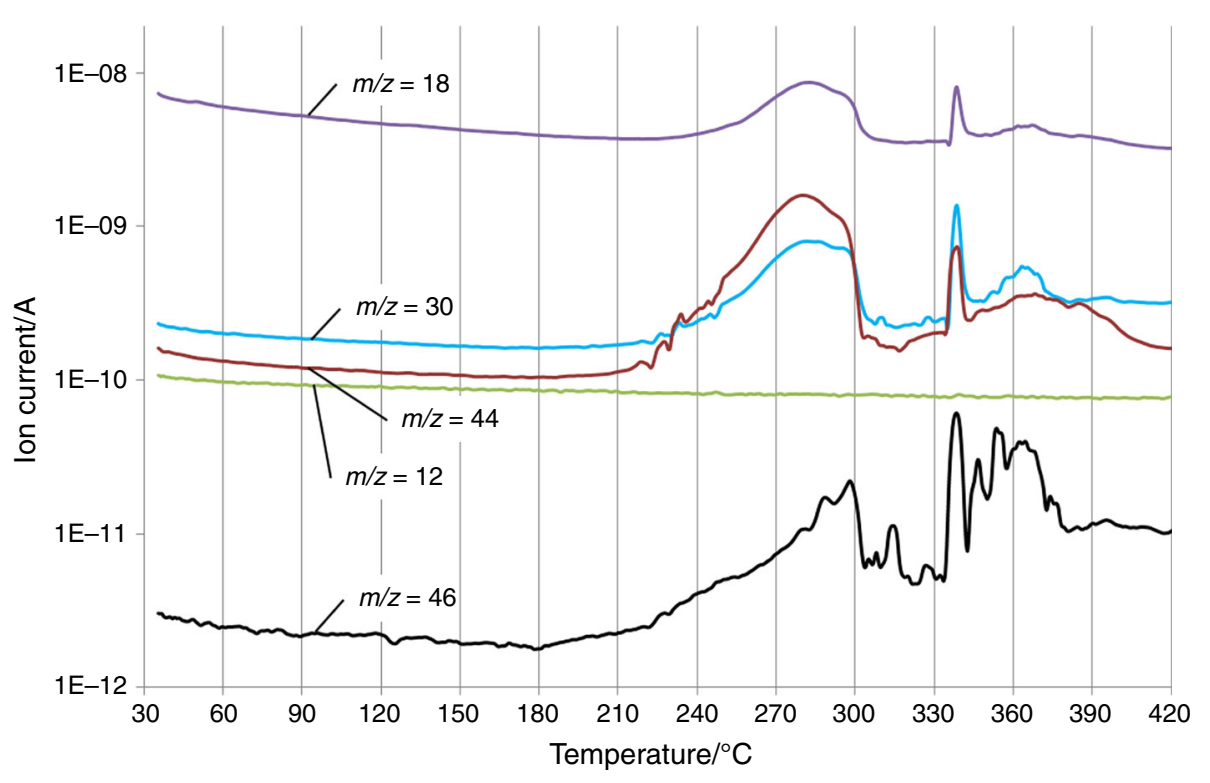


Fig. 3 Result of DTA-TG measurement of the CAN sample containing W1 filler prepared according to the I method (solid line) and II method (dashed line)

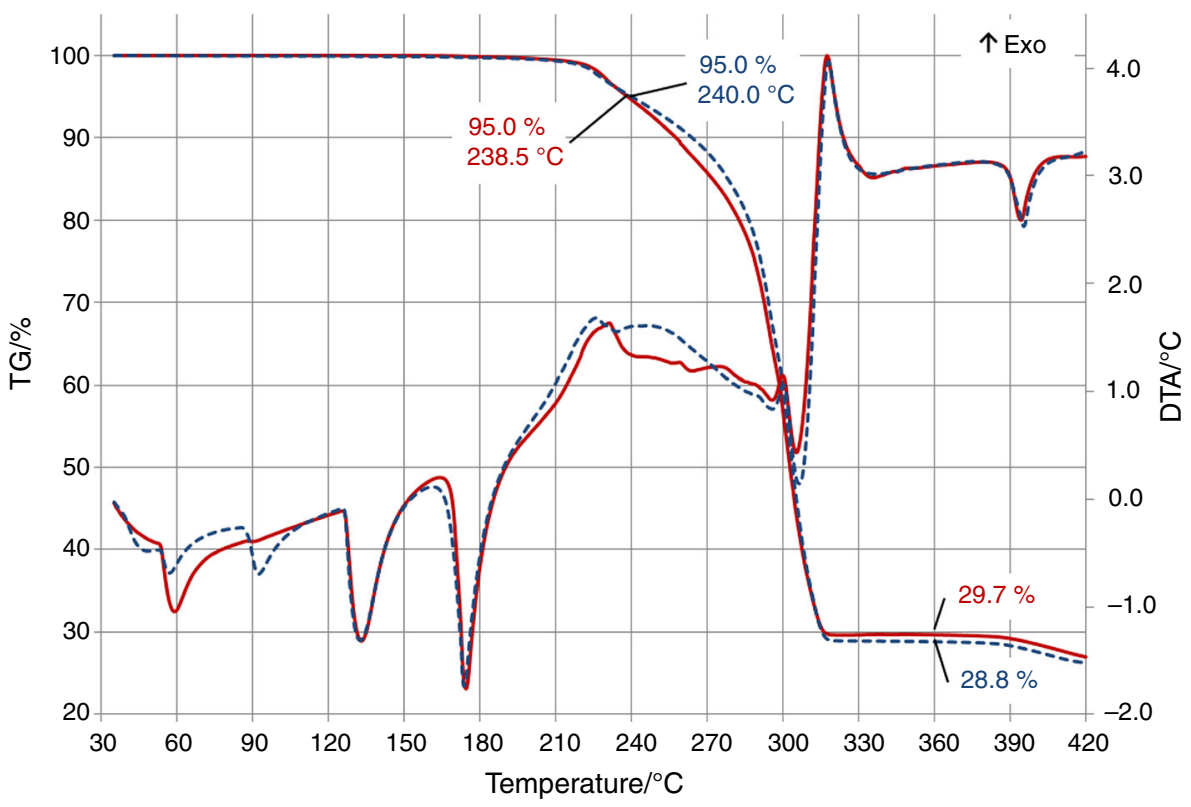

Fig. 4 Result of MS measurement of the CAN sample containing W1 filler prepared according to the I method

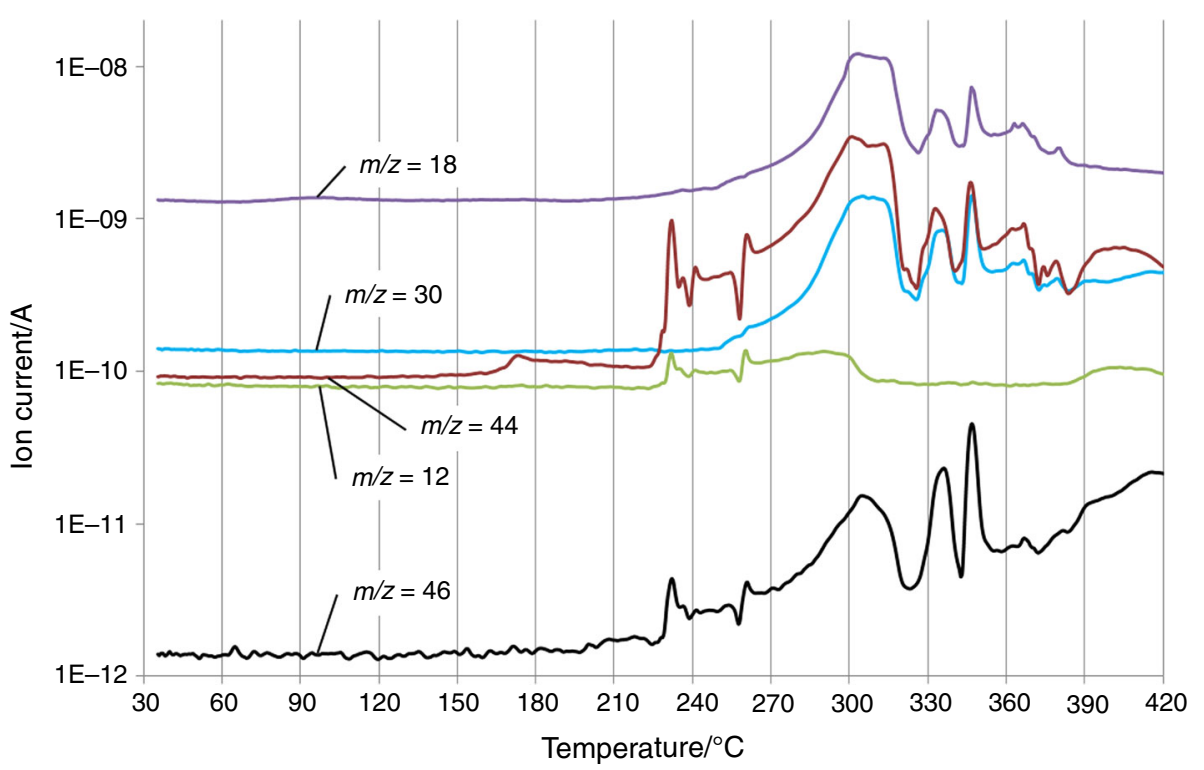

ammonium nitrate, preventing it from self-sustaining exothermic decomposition. Additionally, ammonia produced in these reactions slows down the decomposition of ammonium nitrate, and thus, a strong exothermic effect is not observed until $300{ }^{\circ} \mathrm{C}$. However, partial degradation of ammonium nitrate below this temperature also occurs, which is confirmed by the presence of nitrogen oxides in a gaseous phase. The positive influence of both fillers is also evidenced by the fact that strongly exothermic decomposition of a residual ammonium nitrate above $300{ }^{\circ} \mathrm{C}$ occurs only after reactions with carbonates come to an end, which can be observed as decreasing concentration of $\mathrm{CO}_{2}$ generated in these reactions.
Mixtures containing limestones W3 (Fig. 7) and W4 (Fig. 9) and prepared in accordance with the first method, up to $140{ }^{\circ} \mathrm{C}$ behaved similar to respective samples with dolomites W1 and W2. However, the endothermic effect associated with the melting of ammonium nitrate began, in their case, at a temperature that was lower by $10-14{ }^{\circ} \mathrm{C}$ (Table 3). It was accompanied by a significant mass loss. Such a course of DTA and TG curves may be associated with simultaneous melting of the ammonium nitrate and its endothermic reactions with the filler. An analysis of gaseous products of decomposition of samples with fillers W3 and W4 seems to confirm this assumption (Figs. 8, 10). The evolution of carbon dioxide started 
Fig. 5 Result of DTA-TG measurement of the CAN sample containing W2 filler prepared according to the I method (solid line) and II method (dashed line)

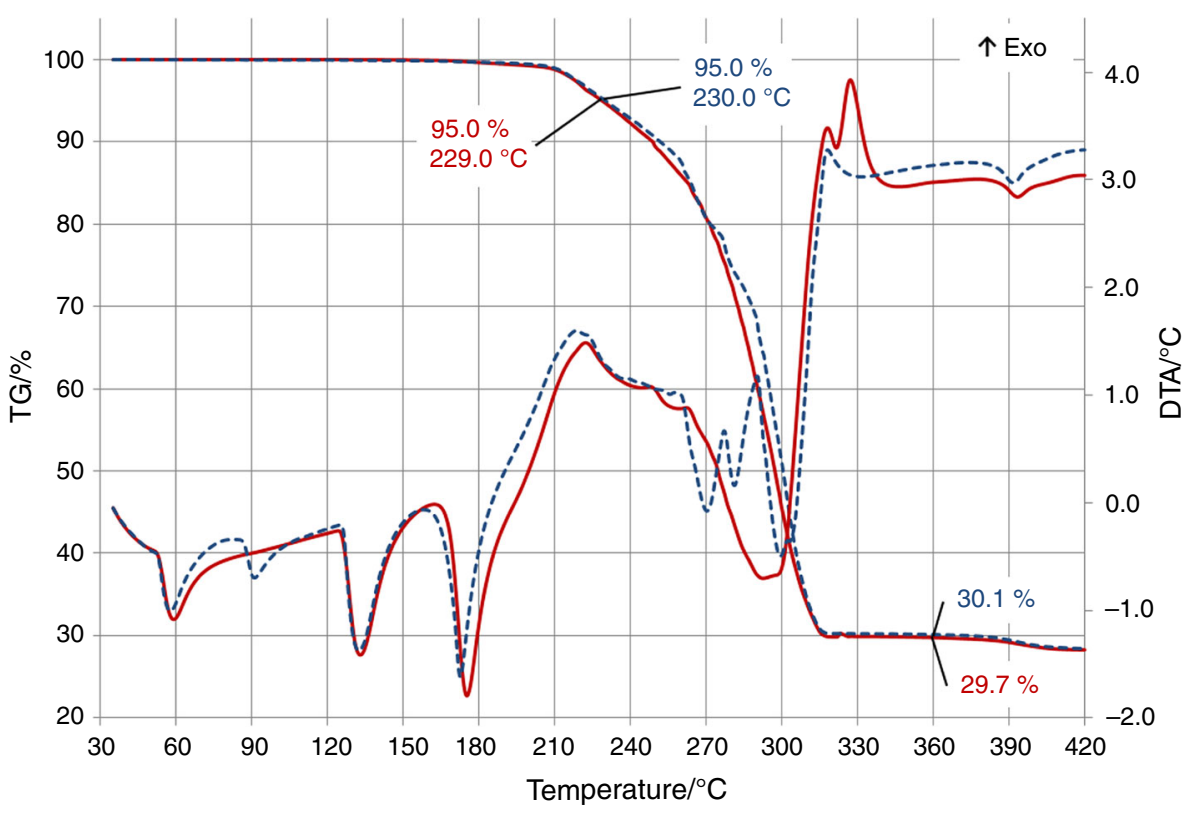

Fig. 6 Result of MS measurement of the CAN sample containing W2 filler prepared according to the I method

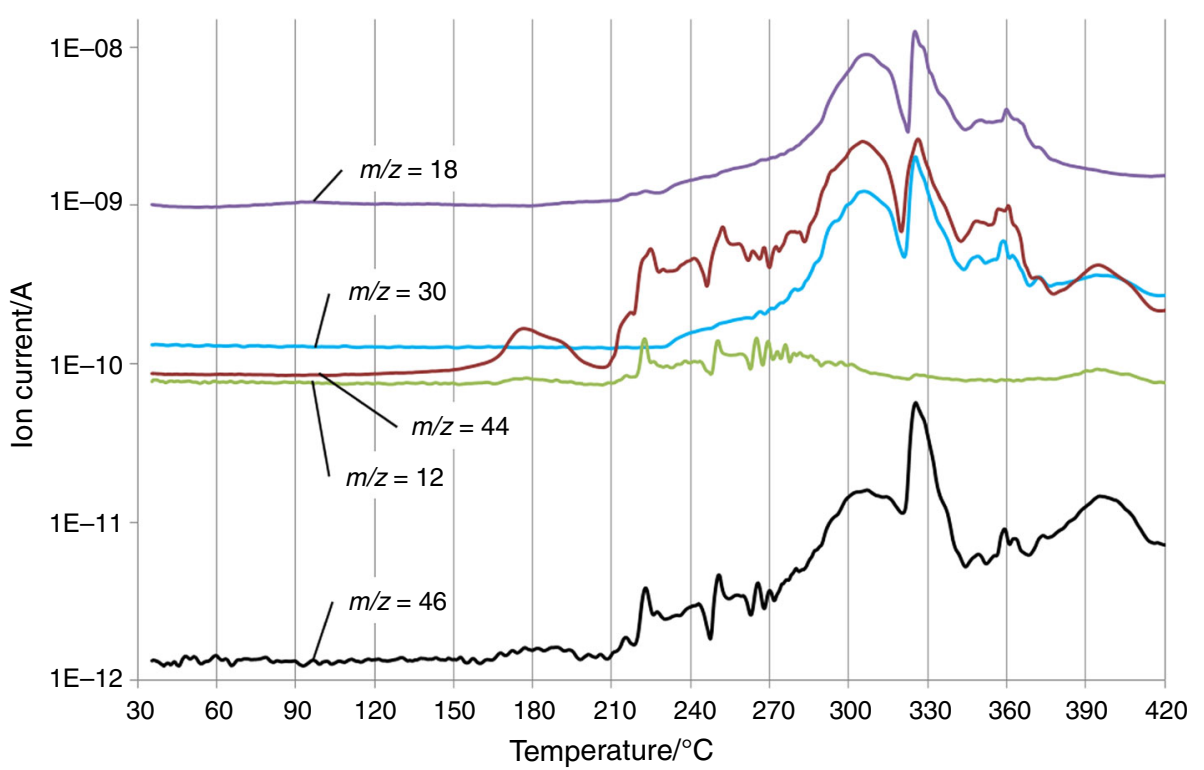

around $130-140{ }^{\circ} \mathrm{C}$ in both cases, proving that fillers W3 and $\mathrm{W} 4$ reacted with ammonium nitrate at a much lower temperature than in case of $\mathrm{W} 1$ and $\mathrm{W} 2$ carbonate minerals. MS signals for nitrogen oxides and water suggest that during the melting of ammonium nitrate, its slow decomposition also began. The significant difference between mixtures with fillers $\mathrm{W} 3$ and $\mathrm{W} 4$ can be seen in total mass loss of the sample. Limestone W3 addition resulted in decomposition of almost $66 \%$ of the sample up to temperature of $360{ }^{\circ} \mathrm{C}$, while in case of filler W4 it was only $63 \%$. This fact suggests that limestone $\mathrm{W} 4$ is more efficient in suppressing the decomposition of fertiliser mixture.
Thermal analysis results for sample of ammonium nitrate with addition of filler W5 (Fig. 11) are entirely different from any previous results in this study. The first registered phase transition, typical for ammonium nitrate, was IV $\rightarrow$ III change. It was followed by another endothermic effect occurring in temperature close to the III $\rightarrow$ II phase transition, which was not observed in any other tested CAN mixture. The presence of this endotherm usually results from higher moisture content in the sample. Due to significant concentration of highly reactive calcium oxide in the filler W5, evolution of small amounts of ammonia and water was observed during sample preparation. It suggests considerable reactivity of the filler, even in 
Fig. 7 Result of DTA-TG measurement of the CAN sample containing W3 filler prepared according to the I method

Fig. 8 Result of MS measurement of the CAN sample containing W3 filler prepared according to the I method
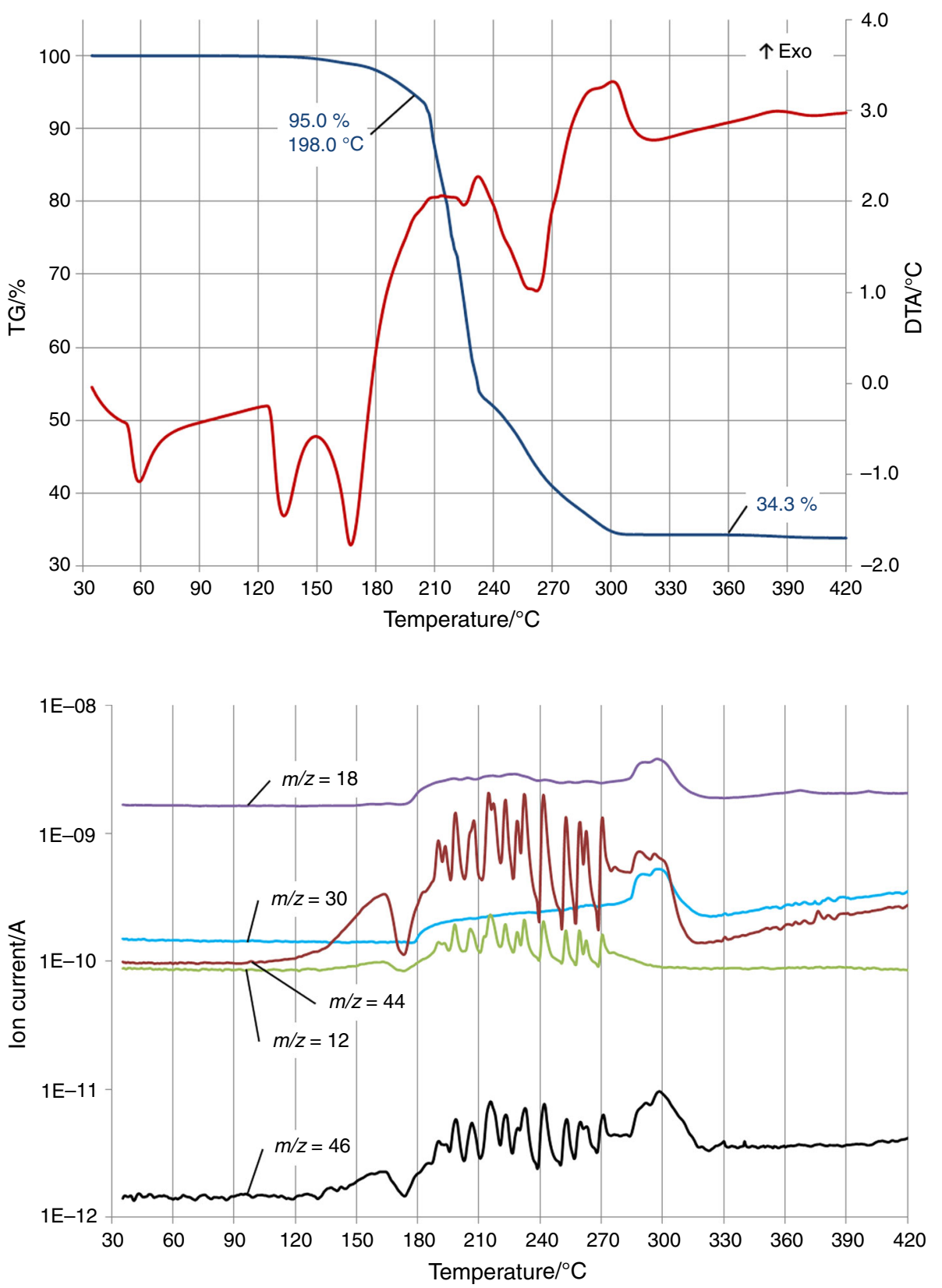

a room temperature. Continuous decrease in sample's mass and evolution of water (Fig. 12), which started in $60{ }^{\circ} \mathrm{C}$, seem to confirm this assumption. Reaction of ammonium nitrate with calcium oxide is much less endothermic than corresponding reactions with carbonates [29]. However, its effect might overlap with III $\rightarrow$ II phase transition, generating wide endotherm observed around $90{ }^{\circ} \mathrm{C}$. The course of DTA curve above $120^{\circ} \mathrm{C}$ also proves that not much of ammonium nitrate was preserved up to this temperature. It is evidenced by the absence of II $\rightarrow$ I phase transition at around $126{ }^{\circ} \mathrm{C}$ and melting of ammonium nitrate in $169^{\circ} \mathrm{C}$. Based on the $\mathrm{CO}_{2}$ evolution, it can be noted that intensive reactions of ammonium nitrate with carbonates occurred in a temperature range $180-240{ }^{\circ} \mathrm{C}$.
Although the mass loss of the sample is the lowest in case of addition of W5 filler, it is a result of high content of calcium and magnesium nitrates produced in reactions of ammonium nitrate with filler. Due to the high reactivity of filler W5, even in temperature of CAN fertiliser production, those compounds would also be present in a final product in large amounts, significantly changing its intended composition.

\section{Mixtures with fillers: II sample preparation method}

Based on the results of thermal analysis of fertiliser samples prepared in accordance with the first method, the best carbonate minerals were selected for further tests. 
Fig. 9 Result of DTA-TG measurement of the CAN sample containing W4 filler prepared according to the I method (solid line) and II method (dashed line)

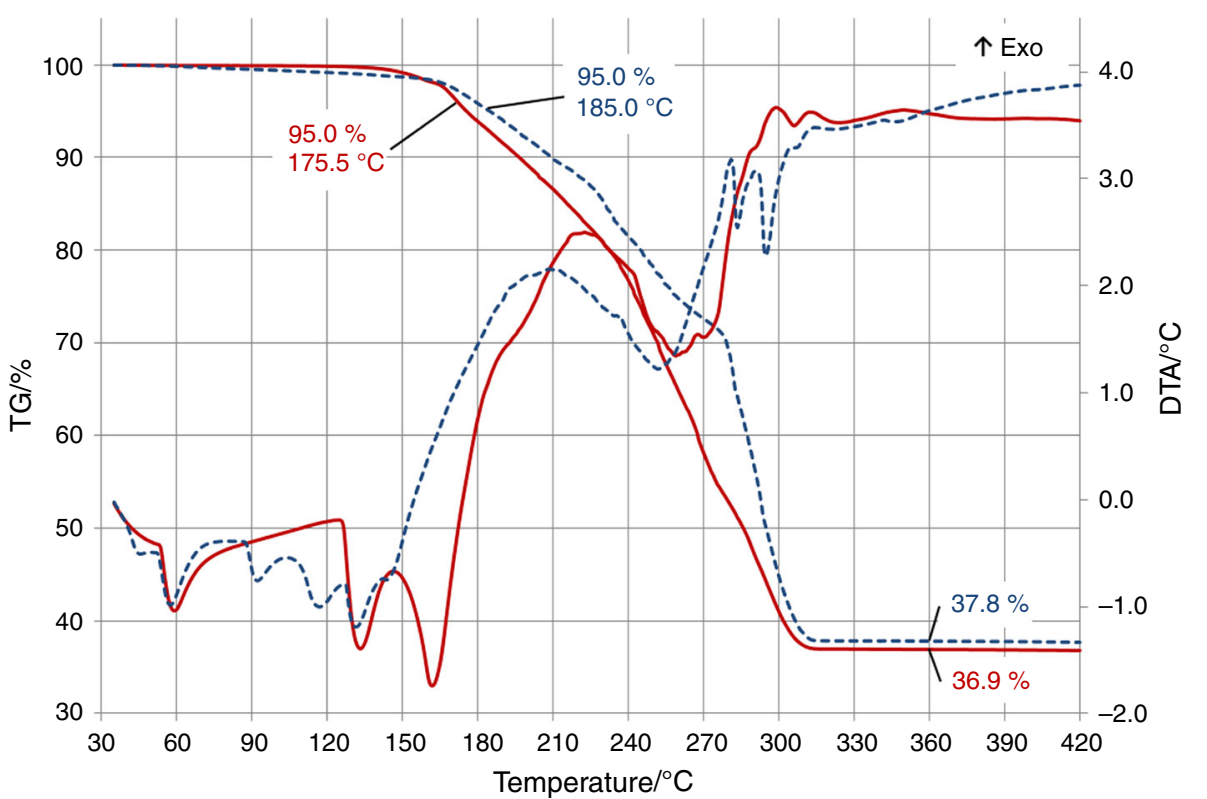

Fig. 10 Result of MS measurement of the CAN sample containing W4 filler prepared according to the I method

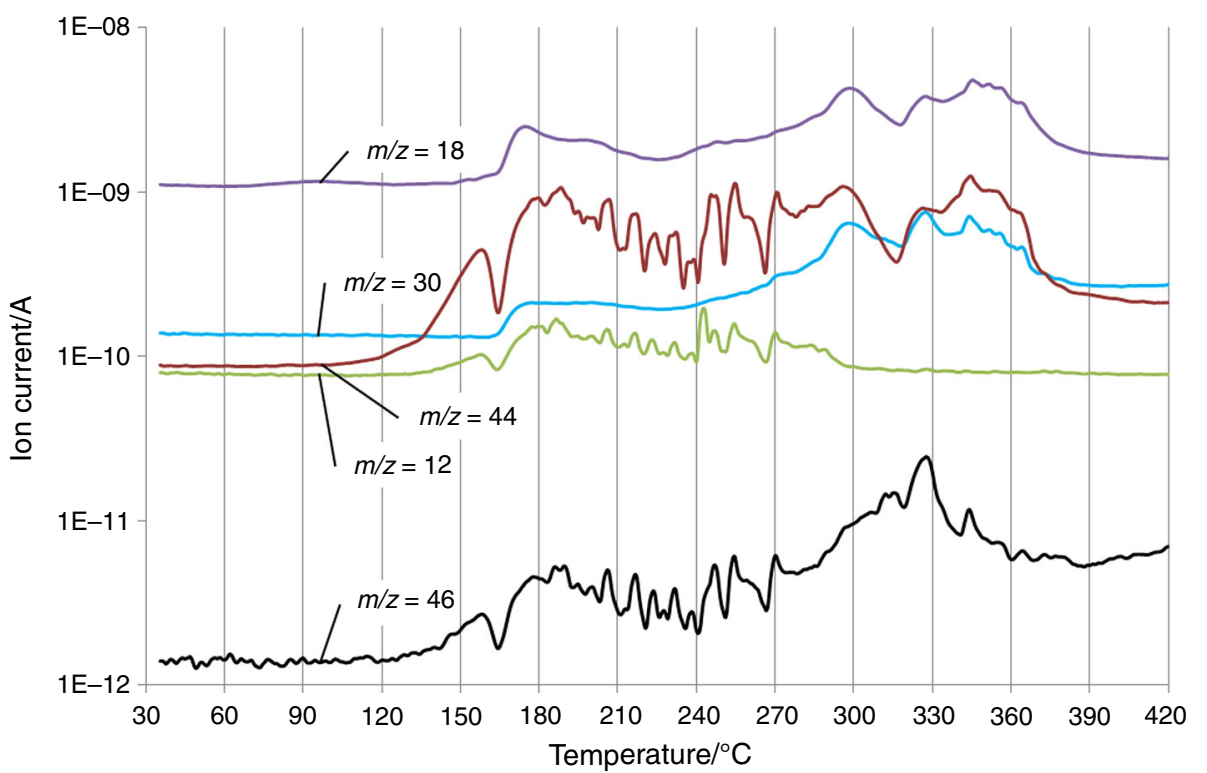

Dolomites $\mathrm{W} 1$ and $\mathrm{W} 2$ reacted with ammonium nitrate above $200{ }^{\circ} \mathrm{C}$, suppressing its exothermic decomposition. However, below this temperature their reactivity was very low, which assures an unchanged composition of a final product. Thus, the influence of fillers $\mathrm{W} 1$ and W2 seems to be favourable in terms of fertiliser production process. Limestones W3 and W4 also reduced the exothermic effect of decomposition of ammonium nitrate. However, their interactions started in much lower temperature range, typical for CAN fertiliser production. Therefore, their addition may result in a changed composition of a final product. Nevertheless, for comparison purposes, limestone providing lower mass loss of the sample and containing less silica, i.e. filler W4, was chosen for further research. Filler W5 turned out to be definitely too reactive with ammonium nitrate, and it was eliminated from further tests. As a result, fillers $\mathrm{W} 1, \mathrm{~W} 2$ and $\mathrm{W} 4$ were used to prepare samples in accordance with the second method. This preparation procedure was intended to mimic the CAN fertiliser production process, so that the effects registered during thermal analysis of thus prepared samples would reflect the thermal behaviour of a final fertiliser product during heating.

In the case of the second sample preparation method, for fillers W1 (Fig. 3) and W2 (Fig. 5), the phase transition IV $\rightarrow$ III occurred at temperature around $53{ }^{\circ} \mathrm{C}$, similar to 
Fig. 11 Result of DTA-TG measurement of the CAN sample containing W5 filler prepared according to the I method

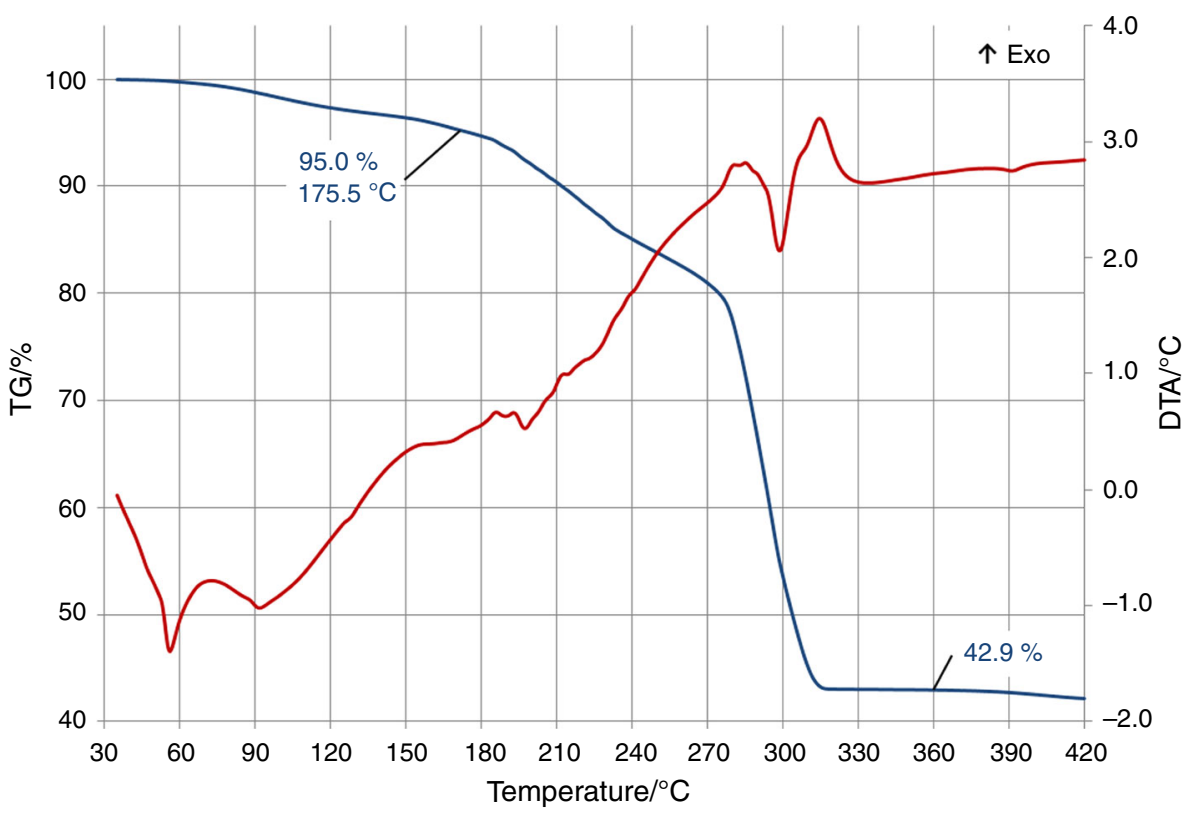

Fig. 12 Result of MS measurement of the CAN sample containing W5 filler prepared according to the I method

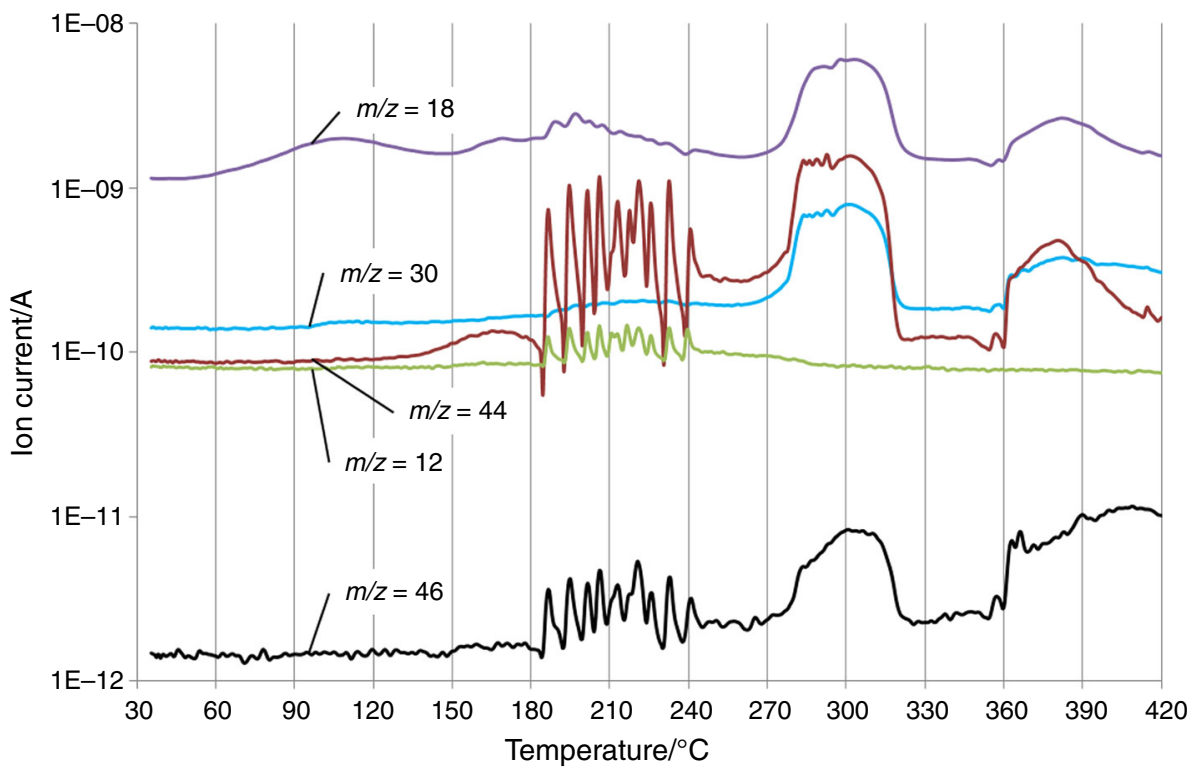

samples prepared in accordance with the first method. Since this transformation is accompanied by a volume change of the crystal structure, oscillation around the transition temperature may cause cracking of granules, and generation of porosity increasing the susceptibility of fertiliser to detonation. Moving this transformation beyond temperature range typical for the transport and storage of fertiliser would be desirable, both from the point of view of safety and of product quality. In contrast to the first method, in samples prepared according to the second method, transformation III $\rightarrow$ II did not disappear. This can be caused by a higher moisture content resulting from water addition during the melting of ammonium nitrate. The temperatures of the endotherm beginning and the exotherm maximum are slightly lower for samples prepared using the second method. Those differences are more significant in the case of mixtures with filler W2. This may suggest that some small part of the carbonate mineral already reacted with ammonium nitrate during sample preparation, which simulated the CAN fertiliser production process, and therefore, beneficial influence of the filler during heating of obtained product is slightly weaker. This observation is also reflected in a less endothermic effect at a temperature range of $230-300{ }^{\circ} \mathrm{C}$ for samples with both 
fillers prepared in accordance with the second method. Nevertheless, the results of thermal analysis of samples with fillers $\mathrm{W} 1$ and $\mathrm{W} 2$ are both similar to those obtained for commercial CAN fertilisers, which are regarded as safe and stable products $[32,35]$.

The DTA results for the sample with filler W4 (Fig. 9) that was prepared according to the second method are consistent with previous observations regarding first method of sample preparation. Carbonate filler reacted to such an extent with ammonium nitrate during sample preparation, which was intended to simulate the fertiliser production process, that the thermal analysis results for this sample are significantly different from those obtained for other tested mixtures. It is presumably caused by a complex composition of this sample, containing considerable amount of calcium nitrate generated during mixture preparation. The endothermic effect starting at $103.7^{\circ} \mathrm{C}$ cannot be associated with any phase transition of ammonium nitrate. Melting of a double salt $5 \mathrm{Ca}\left(\mathrm{NO}_{3}\right)_{2} \cdot \mathrm{NH}_{4} \mathrm{NO}_{3} \cdot 10 \mathrm{H}_{2} \mathrm{O}$, which might be formed during preparation of the sample, seems to be the most probable explanation of this phenomenon, since its melting point is $100-105^{\circ} \mathrm{C}$ [2]. This process, together with evolved crystallisation water, might ease melting of the remaining solid ammonium nitrate, which has presumably undergo simultaneous phase transition II $\rightarrow$ I and melting up to $144.6{ }^{\circ} \mathrm{C}$. This would explain the lack of endothermic effect around $169^{\circ} \mathrm{C}$ in the case of this sample. Other hydrates of calcium and magnesium nitrates might also influence the course of DTA curve. Regardless of the safety of such mixture, after industrial production process the final fertiliser composition would be certainly different from the planned one, which is inacceptable.

\section{Reactivity of carbonate fillers}

The thermal analysis of the prepared samples proved that in all tested mixtures, the reactions between ammonium nitrate and filler took place. The temperature of the beginning of these changes and their intensity was, however, varied. As a result of the occurring reactions, significant quantities of low molecular products were evolved, while part of the ammonium nitrate was converted to the much more stable calcium and magnesium nitrates. Consequently, the residual mass of the sample at $360{ }^{\circ} \mathrm{C}$ was dependent on the filler's reactivity. In the case of mixtures with dolomites $\mathrm{W} 1$ and $\mathrm{W} 2$, it was close to $30 \%$; for limestone $\mathrm{W} 3$, it was around $34 \%$; in the case of filler W4, the residual mass reached $37 \%$, while for filler W5, it was around $43 \%$. The fact that residual mass of the sample is higher than initial content of the filler is caused by partial transformation of carbonates or oxides into nitrates. Therefore, increasing residual mass of the sample indicates considerably changed composition of the mixture, including more thermally stable nitrates. Taking into account the initial amount of ammonium nitrate and added filler, residual mass of a sample at $360{ }^{\circ} \mathrm{C}$ and molar masses of carbonates, oxides and nitrates, it is possible to estimate how much of ammonium nitrate reacted with each filler. The results of calculations according to Eq. (3) are presented in Table 4.

$X=\frac{2 M_{\mathrm{AN}}\left(m_{\mathrm{R}}-m_{\mathrm{F}, 0}\right) 100}{m_{\mathrm{AN}, 0}\left(2 M_{\mathrm{NO}_{3}}-M_{\mathrm{CO}_{3}}\right)}$

where $X$ conversion of ammonium nitrate $(\%), m_{\mathrm{AN}, 0}$ initial mass of ammonium nitrate $(\mathrm{mg}), m_{\mathrm{F}, 0}$ initial mass of the filler $(\mathrm{mg}), m_{\mathrm{R}}$ residual mass of the sample $(\mathrm{mg}), M_{\mathrm{i}}$ molar masses of $\mathrm{NH}_{4} \mathrm{NO}_{3}, \mathrm{NO}_{3}^{-}, \mathrm{CO}_{3}^{2-}$.

In the case of conversion of ammonium nitrate in the mixture with filler W5, containing only about 20 mass\% of carbonates and significant amount of calcium oxide, Eq. (3) was slightly modified. The difference between the residual mass of the sample and the initial mass of added filler was not only associated with substitution of carbonates by nitrates, but it was mainly caused by conversion of oxides to nitrates. Therefore, molar mass of oxygen was also taken into account in calculations. However, it is uncertain whether carbonates and oxides

Table 4 Percentage of ammonium nitrate that reacted with tested fillers

\begin{tabular}{llllll}
\hline Filler & $\begin{array}{l}\text { Sample preparation } \\
\text { method }\end{array}$ & $\begin{array}{l}\text { Initial mass of } \\
\mathrm{NH}_{4} \mathrm{NO}_{3} / \mathrm{mg}\end{array}$ & $\begin{array}{l}\text { Initial mass of } \\
\text { the filler/mg }\end{array}$ & $\begin{array}{l}\text { Residual mass of } \\
\text { the sample/mg }\end{array}$ & $\begin{array}{l}\text { Conversion of } \\
\mathrm{NH}_{4} \mathrm{NO}_{3} / \%\end{array}$ \\
\hline W1 & I & 99.9 & 27.3 & 37.8 & 26.3 \\
& II & 100.0 & 27.3 & 36.7 & 23.5 \\
W2 & I & 100.3 & 27.3 & 37.9 & 26.3 \\
& II & 100.2 & 27.3 & 38.4 & 43.6 \\
W3 & I & 100.0 & 27.2 & 47.0 & 41.0 \\
W4 & I & 100.0 & 27.3 & 48.2 & 52.1 \\
& II & 100.1 & 27.3 & 54.7 & $40.5-44.1$
\end{tabular}


reacted with ammonium nitrate proportionally to their content in the filler, or some of these compounds were converted preferentially. The amount of the same oxides in the mineral was sufficient to cause the measured mass loss. However, the MS signals confirm that $\mathrm{CO}_{2}$ was also released during analysis. Nevertheless, the content of carbonates was not high enough to generate the observed effect independently, especially that calcium oxide is generally more reactive than carbonate. Therefore, the range of conversion of ammonium nitrate with filler W5 presented in Table 4 is limited by two extreme cases. The lower value assumes that only oxides reacted with ammonium nitrate, while the higher value reflects the case in which all carbonates and required part of oxides were converted into nitrates. One should be aware of the fact that data presented in Table 4 are rough estimates based on unavoidable simplifications and generalisations. The results for less reactive fillers are more accurate, while in the case of the most reactive minerals, the calculated values may be overestimated. It is caused by the fact that the latter might react to some extent with ammonium nitrate during sample preparation. In general, it can be observed that in case of fillers W1-W4, higher conversion of ammonium nitrate was reached for minerals containing more $\mathrm{CaCO}_{3}$. Based on the previous observations, filler W5 seems to be the most reactive. However, the calculated conversion of ammonium nitrate during analysis of mixture containing this mineral was lower than for filler W4. It would suggest that considerable amount of calcium oxide reacted before measurement, during sample preparation, which confirms the high reactivity of this mineral and is coherent with lack of any significant endothermic effect during thermal analysis.

Higher reactivity of the carbonate mineral also resulted in the reduction in temperature of noticeable sample mass loss. Therefore, as an indicator of this reactivity, the temperature of $5 \%$ mass loss was chosen. For ammonium nitrate without any additives, this temperature was the highest and equal to $243.5{ }^{\circ} \mathrm{C}$ (Fig. 1). In the case of mixtures containing filler $\mathrm{W} 1$, the $5 \%$ mass loss was reached at $238.5{ }^{\circ} \mathrm{C}$ and $240.0{ }^{\circ} \mathrm{C}$ for the first and the second sample preparation method, respectively (Fig. 3). For dolomite W2, these temperature values were around $230{ }^{\circ} \mathrm{C}$ for both methods (Fig. 5). In the case of limestone W3, the temperature of $5 \%$ mass loss was much lower and equal to $198.0{ }^{\circ} \mathrm{C}$ (Fig. 7). The addition of limestone W4 resulted in even lower temperature of $5 \%$ mass loss (Fig. 9). In the case of the first sample preparation method, it was $175.5^{\circ} \mathrm{C}$, while for the second method, it was $185.0^{\circ} \mathrm{C}$. The lowest value was reached for mixture with filler W5, and it was $175.5^{\circ} \mathrm{C}$ (Fig. 11).

Based on the taken measurements, it can be noted that in case of fillers W1-W4, minerals containing more $\mathrm{CaCO}_{3}$ and having a higher $\mathrm{CaO} / \mathrm{MgO}$ ratio are more reactive with ammonium nitrate. Very high reactivity of filler W5 is caused by considerable content of highly reactive calcium oxide and only about 20 mass $\%$ of carbonates. The influence of the iron, aluminium, silica and trace elements in tested minerals on their reactivity seems to be negligible in comparison with $\mathrm{CaO}$ impact. Even chlorine, sulphur and moisture content in such small amounts do not demonstrate any influence on thermal analysis results. However,
Fig. 13 Simulation of equilibrium composition in a system consisting of ammonium nitrate with calcium and magnesium carbonates from filler W2

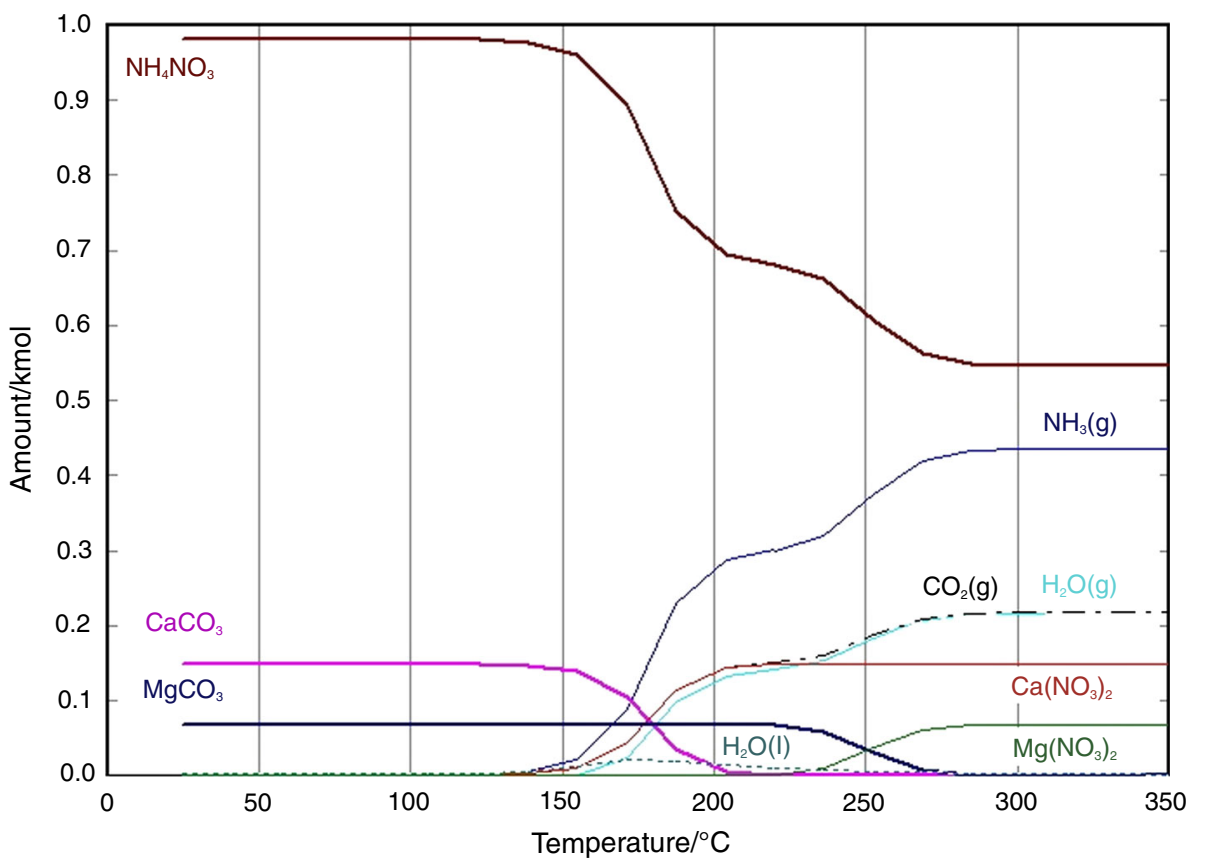


confirmation of these assumptions may require wider range of tests and correlation analysis.

In terms of reactivity, surface area $\left(\mathrm{S}_{\mathrm{BET}}\right)$ of material may be an important factor. In case of tested fillers, increasing reactivity was indeed accompanied by increase in $\mathrm{S}_{\mathrm{BET}}$. However, this dependence is not linear, and for example, limestone W3 having the highest surface area is less reactive than filler W4. Therefore, $\mathrm{CaCO}_{3}$ content seems to be the most important factor influencing the reactivity of a filler. Values of Gibbs energy (Table 1) confirm that reactions between calcium carbonate and ammonium nitrate may occur in lower temperature than in case of magnesium carbonate. Analysis of equilibrium composition simulation shown in Fig. 13 also proves this assumption [29].

As already mentioned, the interaction of the filler with ammonium nitrate in a dangerous situation is desirable; therefore, its reactivity should be significant. However, it cannot react intensively during fertiliser production, i.e. below $150-190{ }^{\circ} \mathrm{C}$. Consequently, the filler W5 is decidedly too reactive to be used for the production of CAN fertilisers. The significant amounts of gases generated as a result of its interaction with ammonium nitrate during the mixing step may lead to the formation of porous granules with adverse physical properties and considerably changed composition. To a certain extent, the same processes may occur in mixtures with fillers W3 and W4. Although they are less reactive than filler W5, they would also significantly change the composition of a final product, lower its quality and increase ammonia losses. The least reactive dolomites W1 and W2 appear to have the most beneficial influence on the thermal stability of ammonium nitrate and, after final verification, both of it may be suitable for use as fillers in production of nitrogen fertilisers. In the case of the less reactive filler $\mathrm{W} 1$, more carbonates are preserved during the production process and are present in the final product in an unchanged form. Therefore, in a hazardous situation, those carbonates contained in the fertiliser can still react with ammonium nitrate, improving the thermal stability of the product. When using the more reactive dolomite W2, carbonates interact with ammonium nitrate more intensively during production of fertiliser, but not as much as in the case of tested limestones. It makes the production process safer due to the presence of released ammonia and the increased endothermic effect. However, less of the filler is preserved in the fertiliser in the original form, and consequently, less of it can react and prevent ammonium nitrate from decomposition in hazardous conditions that the final product may be subjected to. Nevertheless, dolomite W2 was still capable of generating more endothermic effect in the case of samples prepared in accordance with both methods. Therefore, it seems that using filler W2 improves the safety of the fertiliser production process, as well as positively influencing the thermal stability of the final product.

\section{Conclusions}

This research has shown that selected carbonate fillers influence the thermal behaviour of ammonium nitrate to varying degrees. Their addition allows for increasing the temperature of the undesirable IV $\rightarrow$ III phase transition, reducing the possibility of its occurrence during the storage and transport of CAN fertiliser. Furthermore, properly selected fillers may react endothermically with ammonium nitrate at elevated temperatures, reducing the amount of generated heat and leading to the formation of ammonia, which may retard the degradation of the fertiliser, in addition to partially converting ammonium nitrate to more stable calcium and magnesium salts. It was confirmed that reactivity of the filler increases with a rising content of $\mathrm{CaO}$ in the mineral. Too low a level of reactivity may not be sufficient to prevent ammonium nitrate from decomposition, while too high a level of reactivity can cause problems during the production of fertiliser, reducing the effectiveness of filler in the final product, changing its composition and causing significant ammonia losses. Therefore, filler W5 is indubitably too reactive, to be used in CAN fertilisers. The reactivity of fillers W3 and W4 may also be too high in the case of the production process in temperature exceeding $150{ }^{\circ} \mathrm{C}$, whereas dolomites $\mathrm{W} 1$ and $\mathrm{W} 2$ seem to be the most suitable of all tested fillers. They almost do not react with ammonium nitrate in temperature range typical for $\mathrm{CAN}$ fertiliser production, while significantly reducing the exothermic effect of its decomposition over $200{ }^{\circ} \mathrm{C}$. In general, both dolomites may be suitable for the production of CAN fertilisers; however, in terms of the production process safety and thermal behaviour of the final product, dolomite W2 seems to be the best of the examined minerals. Therefore, based on the current tests, it can be concluded that $\mathrm{CaO}$ content below 30 mass\% may be too low for an effective filler, while it also should not excessively exceed 40 mass $\%$.

Presented conclusions concern only the results of the thermal analysis of tested samples. They do not take into consideration other features of a mixture and final product, like granulation properties or liability to detonation. As already mentioned, according to the current EU legislation, only fertilisers containing more than 28 mass $\%$ of nitrogen have to be tested for detonation potential; nevertheless, industrial application of a particular carbonate mineral must be preceded by its final verification. The presented methodology and line of reasoning allow to eliminate fillers that are clearly unsuitable for CAN fertiliser production and select potentially effective fillers for further industrial tests. 
Acknowledgements This work was financially supported by a fellowship that was co-financed by the European Union within the European Social Fund.

Open Access This article is distributed under the terms of the Creative Commons Attribution 4.0 International License (http://crea tivecommons.org/licenses/by/4.0/), which permits unrestricted use, distribution, and reproduction in any medium, provided you give appropriate credit to the original author(s) and the source, provide a link to the Creative Commons license, and indicate if changes were made.

\section{References}

1. Biskupski A, Ochał A, Malinowski P. The effect of technological solutions and process parameters on the quality of the granulated fertilizers containing ammonium nitrate. Przem Chem. 2006;85: 193-200.

2. Aleinov DP. Nitric acid, nitrates, and ammonium salts. In: United Nations Industrial Development Organization, International Fertilizer Development Center, editors. Fertilizer manual. 3rd ed. Dordrecht: Kluwer Academic Publishers; 1998.

3. Recous S, Machet JM, Mary B. The partitioning of fertilizer-N between soil and crop: comparison of ammonium and nitrate applications. Plant Soil. 1992;144:101-11.

4. Juo ASR, Dabiri A, Franzluebbers K. Acidification of a kaolinitic Alfisol under continuous cropping with nitrogen fertilization in West Africa. Plant Soil. 1995;171:245-53.

5. Brentrup F, Küsters J, Kuhlmann H, Lammel J. Application of the life cycle assessment methodology to agricultural production: an example of sugar beet production with different forms of nitrogen fertilizers. Eur J Agron. 2001;14:221-33.

6. Higgins S, Morrison S, Watson CJ. Effect of annual applications of pelletized dolomitic lime on soil chemical properties and grass productivity. Soil Use Manag. 2012;28:62-9.

7. Abbasi MK, Tahir MM, Rahim N. Effect of $\mathrm{N}$ fertilizer source and timing on yield and $\mathrm{N}$ use efficiency of rainfed maize (Zea mays L.) in Kashmir-Pakistan. Geoderma. 2013;195:87-93.

8. Kołaczkowski A, Pękalski A, Meissner Z. Estimation of the liability to detonating of prilled ammonium nitrate fertiliser grade. J Loss Prev Process Ind. 2000;13:555-61.

9. Turcotte R, Lightfoot PD, Fouchard R, Jones DEG. Thermal hazard assessment of AN and AN-based explosives. J Hazard Mater. 2003;A101:1-27.

10. Oxley JC, Smith JL, Rogers E, Yu M. Ammonium nitrate: thermal stability and explosivity modifiers. Thermochim Acta. 2002;384:23-45.

11. Chaturvedi S, Dave PN. Review on thermal decomposition of ammonium nitrate. J Energ Mater. 2013;31:1-26.

12. Cagnina S, Rotureau P, Fayet G, Adamo C. The ammonium nitrate and its mechanism of decomposition in the gas phase: a theoretical study and a DFT benchmark. Phys Chem Chem Phys. 2013;15:10849-58.

13. Izato Y, Miyake A. Thermal decomposition of molten ammonium nitrate (AN). J Therm Anal Calorim. 2015;122:595-600.

14. Vyazovkin S, Clawson JS, Wight CA. Thermal dissociation kinetics of solid and liquid ammonium nitrate. Chem Mater. 2001;13:960-6.

15. Olszak-Humienik M. On the thermal stability of some ammonium salts. Thermochim Acta. 2001;378:107-12.

16. Irikura $\mathrm{KK}$. Thermochemistry of ammonium nitrate, $\mathrm{NH}_{4} \mathrm{NO}_{3}$, in the gas phase. J Phys Chem A. 2010;114:11651-3.

17. Hildenbrand DL, Lau KH, Chandra D. Revised thermochemistry of gaseous ammonium nitrate, NH4NO3(g). J Phys Chem A. 2010;114:11654-5.
18. Li XR, Koseki H. Study on the contamination of chlorides in ammonium nitrate. Process Saf Environ Prot. 2005;83(B1):31-7.

19. Sun J, Sun Z, Wang Q, Ding H, Wang T, Jiang C. Catalytic effects of inorganic acids on the decomposition of ammonium nitrate. J Hazard Mater. 2005;B127:204-10.

20. Rubtsov YI, Kazakov AI, Lempert DB, Manelis GB. Kinetic regularities of the heat release for the interaction of some organic compounds with ammonium nitrate. Propellants Explos Pyrotech. 2006;31:421-34

21. Popławski D, Hoffmann J, Grzesiak D, Kędzior R, Hałat A, Falewicz P. Scanning calorimetry as a method for testing safety hazards connected with ammonium nitrate-involving chemical reactions. Przem Chem. 2013;92:2158-61.

22. Izato $\mathrm{Y}$, Miyake A. Thermal decomposition mechanism of ammonium nitrate and potassium chloride mixtures. J Therm Anal Calorim. 2015;121:287-94.

23. Dechy N, Bourdeaux T, Ayrault N, Kordek MA, Le Coze JC. First lessons of the Toulouse ammonium nitrate disaster, 21st September 2001, AZF plant, France. J Hazard Mater. 2004;111:131-8.

24. Wrzesiński JA, Popławska J, Kołaczkowski A, Biskupski A. Accidents and disasters connected with ammonium nitrate decomposition. Case study. Przem Chem. 2013;92:2173-7.

25. Zygmunt B, Buczkowski D. Agriculture grade ammonium nitrate as the basic ingredient of massive explosive charges. Propellants, Explos, Pyrotech. 2012;37:685-90.

26. Pittman W, Han Z, Harding B, Rosas C, Jiang J, Pineda A, Mannan MS. Lessons to be learned from an analysis of ammonium nitrate disasters in the last 100 years. J Hazard Mater. 2014;280:472-7.

27. Rubtsov YI, Kazakov AI, Rustambekov MK, Starshinov MS Kinetic aspects and heats of reaction between components in thermal decomposition of ammonium nitrate-calcium (magnesium) carbonate mixtures. Russ J Appl Chem. 2005;78:1795-800.

28. Klimova I, Kaljuvee T, Türn L, Bender V, Trikkel A, Kuusik R. Interactions of ammonium nitrate with different additives. J Therm Anal Calorim. 2011;105:13-26.

29. HSC Chemistry ${ }^{\circledR}$ for Windows. Chemical reaction and equilibrium software with extensive thermochemical database. Version 7.11. Outotec Research Center, Licence for Wroclaw University of Technology.

30. Ryshchenko IM, Kulatskii NS, Savenkov AS, Protiven IN, Ratushnaya LN. Enhancing the strength of granules and thermal stability of ammonium nitrate. Russ J Appl Chem. 2008;81:743-7.

31. Kaljuvee T, Edro E, Kuusik R. Influence of lime-containing additives on the thermal behaviour of ammonium nitrate. J Therm Anal Calorim. 2008;92:215-21.

32. Biskupski A, Myka A, Borowik M, Malinowski P. Evaluation of reactivity of carbonate filler powders applied in nitrogen fertilizer technology. Przem Chem. 2013;92:1341-5.

33. Tynsuaadu K, Viisimaa L. Differential thermal analysis for estimation of the thermal stability of NPK fertilizers. J Therm Anal. 1991;37:927-34.

34. Pelovski Y. Thermal analysis for control of the properties of mineral fertilizers. J Therm Anal Calorim. 2000;60:53-8.

35. Popławski D, Grzesiak D, Kaniewski M, Wójcik M, Hoffmann J. The thermal stability of selected commercial ammonium nitratecontaining fertilizers. Przem Chem. 2015;94:1000-4.

36. Regulation (EC) No 2003/2003 of the European Parliament and of the Council of 13 October 2003 relating to fertilisers.

37. Kiiski H. Properties of ammonium nitrate based fertilisers. PhD Thesis, Helsinki: University of Helsinki; 2009.

38. Bissell HJ, Chilingar GV. Chapter 4-classification of sedimentary carbonate rocks. In: Chilingar GV, Bissell HJ, Fairbridge $\mathrm{RW}$, editors. Carbonate rocks, origin, occurrence and classification. Amsterdam: Elsevier Publishing Company; 1967. 